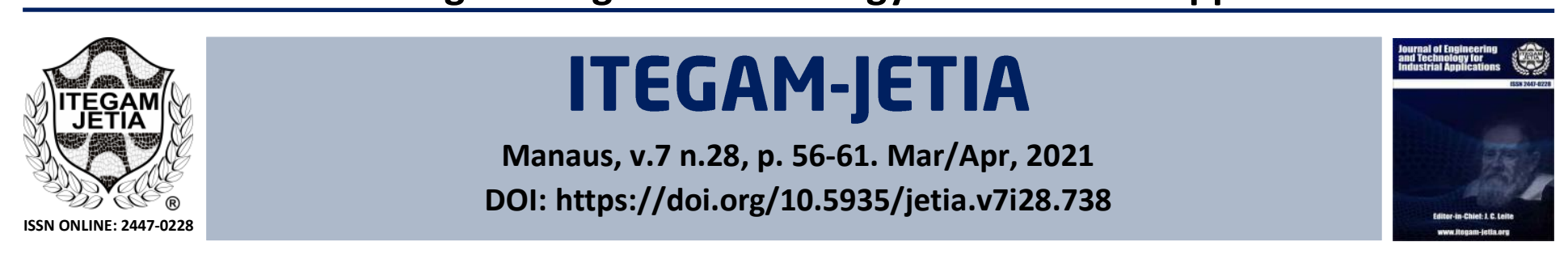

\title{
GSM BASED SMART FIRE AND HIGH-TEMPERATURE DETECTION SYSTEM
}

\author{
Ravindra Koggalage*1, Manjula Welihinda ${ }^{2}$ and Hasitha Nuwan ${ }^{3}$ \\ ${ }^{1}$ Dean, Faculty of Engineering Technology, University of Vocational Technology, Sri Lanka. \\ ${ }^{2}$ Deputy General Manager, ACL Cables PLC, Sri Lanka. \\ ${ }^{3}$ Department of Electrical \& Electronics Technology, University of Vocational Technology, Sri Lanka. \\ ${ }^{1}$ http://orcid.org/0000-0003-0746-3203 (i), ${ }^{2}$ http://orcid.org/0000-0002-6408-5432 (i), ${ }^{3}$ http://orcid.org/0000-0002-9112-4425 (D)
}

Email: *koggalage@yahoo.com, manjuslw@yahoo.com, hasitha.800@gmail.com

\section{ARTICLE INFO}

\section{Article History}

Received: February $13^{\text {st }}, 2021$

Accepted: April 13 ${ }^{\text {th }}, 2021$

Published: April 30 ${ }^{\text {th }}, 2021$

\section{Keywords:}

Smoke Sensor,

Temperature Sensor,

GSM Module,

SMS Alert,

Arduino Board.

\begin{abstract}
This research refers to an Arduino and Global System for Mobile (GSM) based system for efficient detection of fire hazards. This project's purpose is industrial and domestic safety, and the primary concern is to avoid the fire hazards that occur to the employees and the properties inside the buildings. As a solution, a smart fire and high-temperature detection system is design using GSM technology, smoke/temperature sensors, and Arduino technology. A smoke sensor is used to detect the smoke from the fire and a temperature sensor is used to detect temperature increase inside the building. In event of a fire, an alert message will be sent to the user via short message service (SMS) via the GSM module. Furthermore, when a fire is detected, a signal will be sent to the main power supply circuit breaker via a microcontroller and then the power supply of the particular building will shut down. Results from the test are documented and discussed in this paper. This system helps users to respond immediately to the situation and so improve their safety by protecting their lives and the properties from a disaster.
\end{abstract}

\section{INTRODUCTION}

An increase in temperature or fire occurred in remote locations, where human interaction is limited, is a major cause for deaths and disasters in industrial areas and factories. Due to poor fire extinguishing arrangements, lack of adequate fire alarm, and emergency exit, the extent of the disaster could worsen. Nowadays people can take the advantage of the technology to provide early warnings and alerts to avoid danger and to react quickly. When temperature increase or fire occurred in remote locations, technology is the best thing we can use.

This project will be used in a "Solar inverter room" for high temperature and fire detection. For this purpose, the project has used highly sensitive smoke (MQ5) and temperature (DHT11) detectors, by which the microcontroller will get a high pulse at the input pin which is preprogrammed for desired output signals.

This project also uses an alert warning system based on Global System for Mobile (GSM) network. When a temperature increase or fire occurs, the sensors used in a circuit will detect it and GSM modem (SIM 900) will send out an SMS alert to the person-in-charge of the "Solar inverter room", to the head of the particular department, and the security guard room. This will allow those persons to respond quickly. This system can also be installed in other places like food storage rooms, cool rooms, powerhouses, hotels, buildings, and any other places where fire and temperature are highly controlled.

\section{LITERATURE REVIEW}

In 2011 L Chun-yuan has designed an intelligent fire alarm system based on GSM. The purpose of the project is to solve the problem of complex cabling, missed declaration, and missing alarm of traditional fire alarm system [1]. By adapting smoke detectors and using a variable threshold alert algorithm with temperature compensation the accuracy of the fire alarm is improved.

In 2014 M Faris, M Fuzi, A F Ibrahim, M. H. Ismail, N. Syakira, and A. Halim, has developed a low-cost home dedicated fire alert detection system using ZigBee wireless network. Along with ZigBee an Arduino Uno microcontroller, Arduino digital 
temperature sensor, Buzzer alarm, and X-CTU software were used in the project. It is called "Heat sensor for home use" [2].

In $2016 \mathrm{~S}$ Suresh has developed a home-based fire monitoring and warning system using Arduino Uno R3. During the existence of smoke or flame at a particular level, this system will send an alert to the property owner effectively and quickly via GSM [3].

In $2012 \mathrm{H}$ Elbehiery has designed and developed an intelligent fire alarm system for home fire alarms with an Arduino-based system utilizing GSM Module. This system has an ATmega328 and a temperature sensor along with an Arduino board. The project's purpose is for house safety where the main purpose is to avoid the fire accidents that occurred to the residents and the properties inside the house as well [4].

In 2015 K Sen, J Sarkar, S Saha, A Roy, D Dey, and S Baitalik, has developed an automated fire detection and controlling system based on smoke and heat detection. It is comprised of a combination of electrical/electronic devices/equipment working together to detect the presence of fire and alert people through an audio or visual medium after detection. The system will send Short Message Service (SMS) to the registered mobile numbers and switch on a water sprayer or a solenoid pump to spray water or fire ceasing foam [5].

In 2013 P Y Mulge, has designed remote temperature minoring using a wireless sensor network prototype for remote room temperature monitoring. This network will be used for the management of fire rescue operations. LM35 sensor senses the remote room temperature and temperature status is transmitted to the smartphone via GPRS. This work aims at the monitoring of remote room temperature. This provides an opportunity to quickly respond to fire emergencies [6].

\section{MATERIALS AND METHODS}

The design and development of this project are divided into two main parts which are hardware architecture and software details. In the hardware architecture, the design of the circuit was constructed and the prototype of the project was built. In the software development, the whole complete prototype was operated via programming codes.

\section{III.1 HARDWARE ARCHITECTURE}

Arduino is the mainboard, which is an open-source microcontroller-based kit. The Arduino system offers a set of analog and digital pins that can be interfaced with many other boards and circuits which have different functions in a design. Figure 1 shows the Arduino Uno board that is used throughout the project.

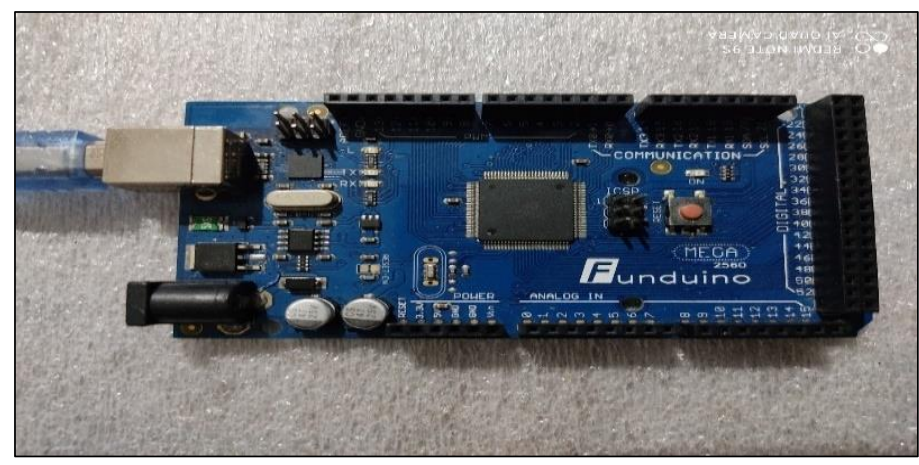

Figure 1: The Arduino Mega board uses a microcontroller ATmega328 onboard.

Source: Authors, (2020).
The GSM module, GSM SIM900A type is selected to carry out the task of communication between Arduino board and mobile phone. Figure 2 shows the GSM SIM900A device before connecting to the Arduino board.

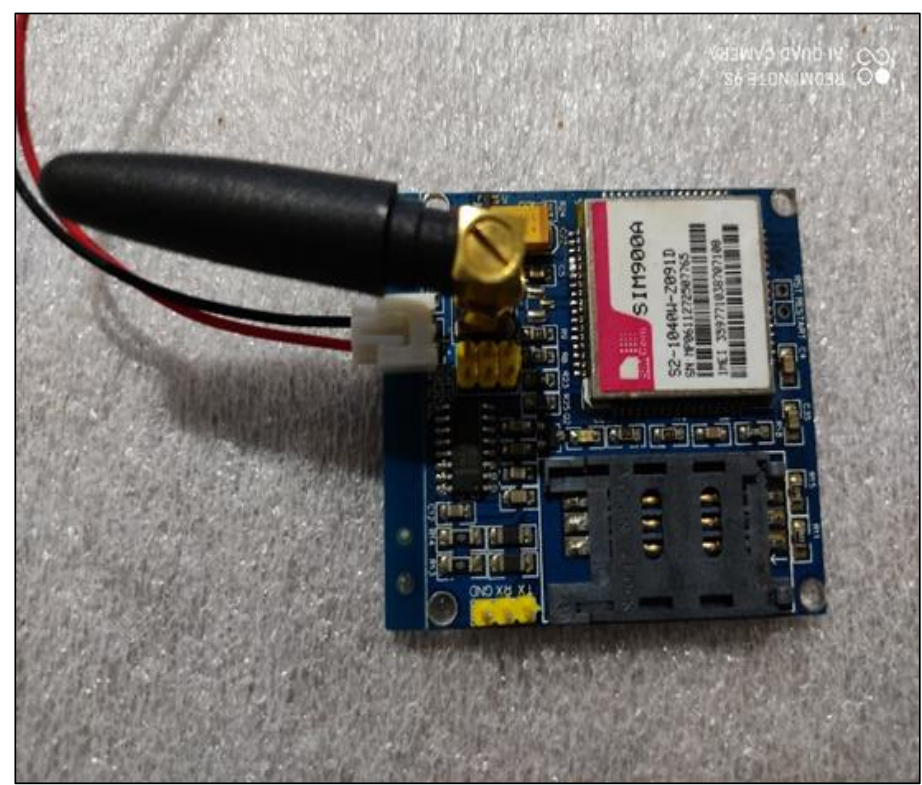

Figure 2: The GSM SIM900A module to communicate with Arduino board.

Source: Authors, (2020).

Temperature/heat sensor (DHT11) is chosen for measuring the temperature, which is a commonly used temperature and humidity sensor. The sensor can measure temperature from $0^{\circ} \mathrm{C}$ to $50^{\circ} \mathrm{C}$ and humidity from $20 \%$ to $90 \%$ with an accuracy of $\pm 1{ }^{\circ} \mathrm{C}$ and $\pm 1 \%$. Figure 3 shows the DHT11 sensor before connecting to the Arduino board.

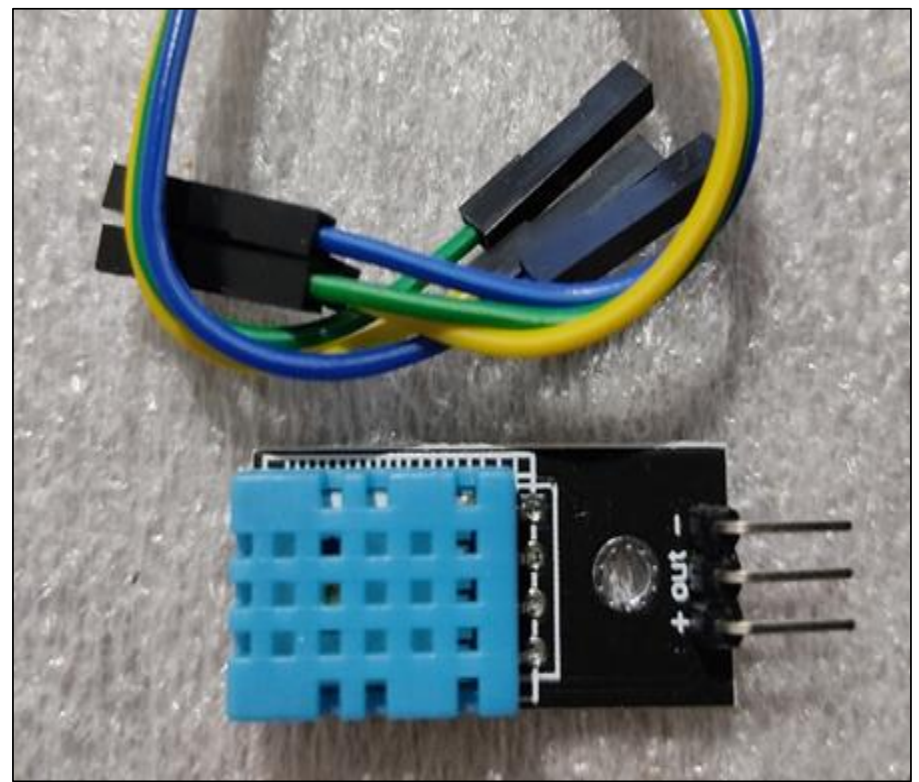

Figure 3: The DHT11 sensor.

Source: Authors, (2020).

To detect the smoke during a fire, a Gas sensor has been used. The project used the MQ5 Gas sensor module. The digital output of the sensor has only two possible outputs - High and Low. Figure 4 shows the MQ5 Gas sensor before connecting to the Arduino board. 


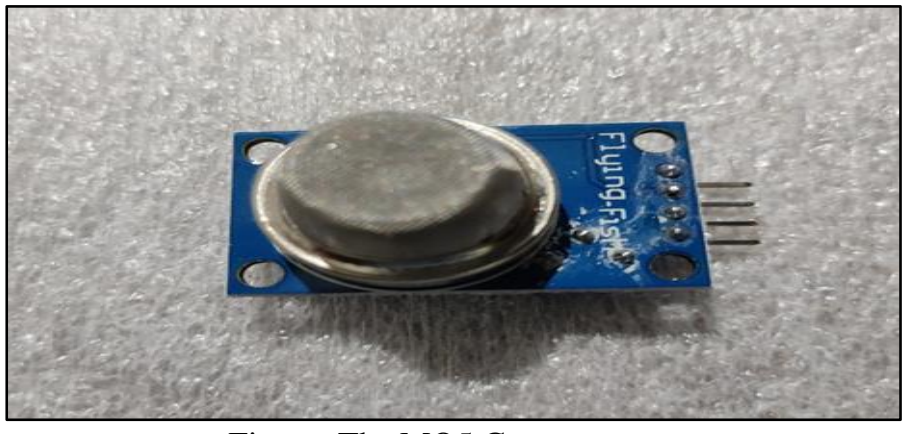

Figure: The MQ5 Gas sensor.

Source: Authors, (2020).

Figure 5 presents the block diagram for the fire and hightemperature detection system. The hardware design entails three main components which are the connections between Arduino board and the GSM SIM900A and Arduino with the temperature sensor (DHT11) and Gas sensor (MQ5).

When a fire has broken out, MQ5 will trigger the smoke. Upon sensing the smoke, it will directly send a signal to the Arduino informing the fire. The smoke will make the Arduino alert the user about the situation through the GSM module. An SMS will be sent promptly to the user to let the user know the existence of the fire. At the same time, a signal will be sent to the main power supply circuit breaker via a microcontroller and then the power supply of the particular building will be shutting down and the existence of the fire will be notified as well on the LCD.

When the temperature is increased in the solar inverter room, DHT11 will trigger the temperature. Upon reaching the temperature of $30 \mathrm{C}$, it will directly send the signal to the Arduino informing the high temperature. The increased temperature will make the Arduino alert the user about the situation through the GSM module. An SMS will be sent promptly to the user to let the user know the temperature increased in the solar inverter room. At the same time, increasing temperature will be notified as well on the LCD.

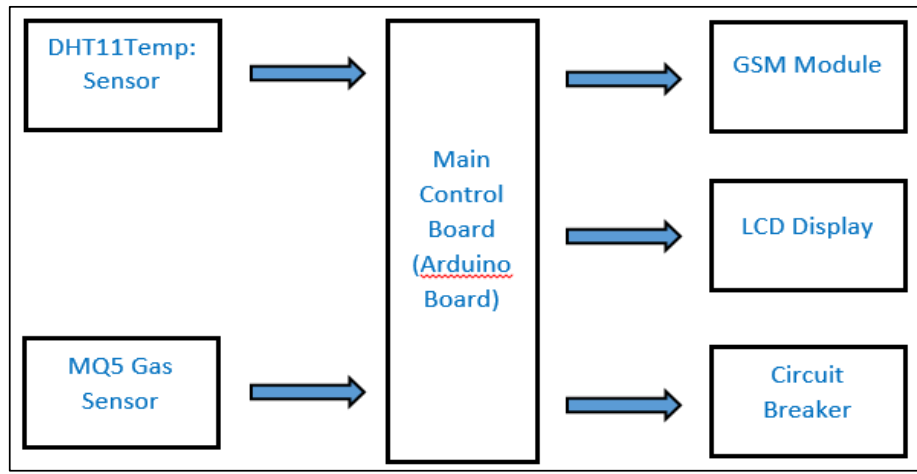

Figure 5: Block diagram of the home fire alert system. Source: Authors, (2020).

\section{III.2 SOFTWARE DEVELOPMENT}

The software of the project is based on the flow chart in figure 6 . When the system begins, DHT11 will always sense the surrounding temperature and MQ5 will sense smoke. Whenever a fire is broken out, even a small little fire, smoke, and temperature rise will have occurred. In that situation, DHT11 can detect the temperature value instantly and MQ5 detect smoke. The DHT11 will detect the temperature changes inside the solar inverter room not only in case of fire but when an air conditioner malfunction occurred. At the time when the temperature reaches $30{ }^{\circ} \mathrm{C}$ or above and the presence of smoke, the microcontroller on the Arduino Mega board will notify the GSM module to send an alert message to the user. And simultaneously send a signal to the main power circuit breaker of the room, so the power supply to the room will be shut off. The value of the temperature limit that can be triggered by DHT11 can be changed in the code upon request by the user. Figure 6 illustrates the flow chart of the fire alert system.

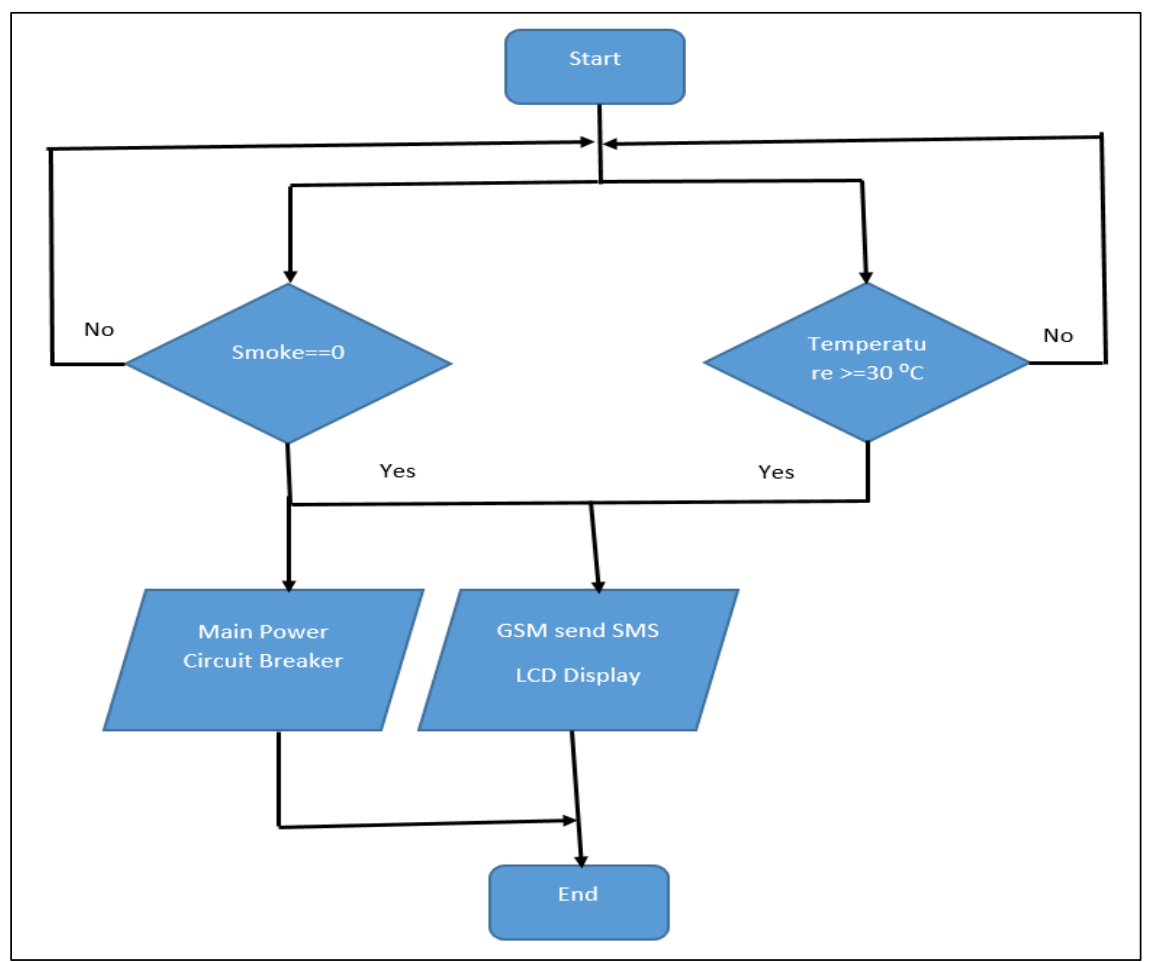

Figure 6: Flowchart of the smoke and temperature alert.

Source: Authors, (2020). 


\section{III.3 SCHEMATIC DIAGRAM}

The overall project schematic diagram is shown in figure 7. While figure 8 illustrates the connection schematic diagram between the Arduino board with DHT11, MQ5, and GSM module. Since the Proteus $\bigodot$ software does not have the GSM module component, it is replaced with the input connector available which the connector pins will be attached directly to the
Arduino board. For the particular part of detecting Smoke from MQ5 and Temperature from DHT11, the code is written and portrayed in figure 9 . In the code, measured temperature from the surrounding is identified in voltage. It is because DHT11 is an analog sensor which values voltage unit. The voltage unit received will then be converted into a comprehensible standard SI unit; degree Celcius in the subroutine called 'CheckTemp()'

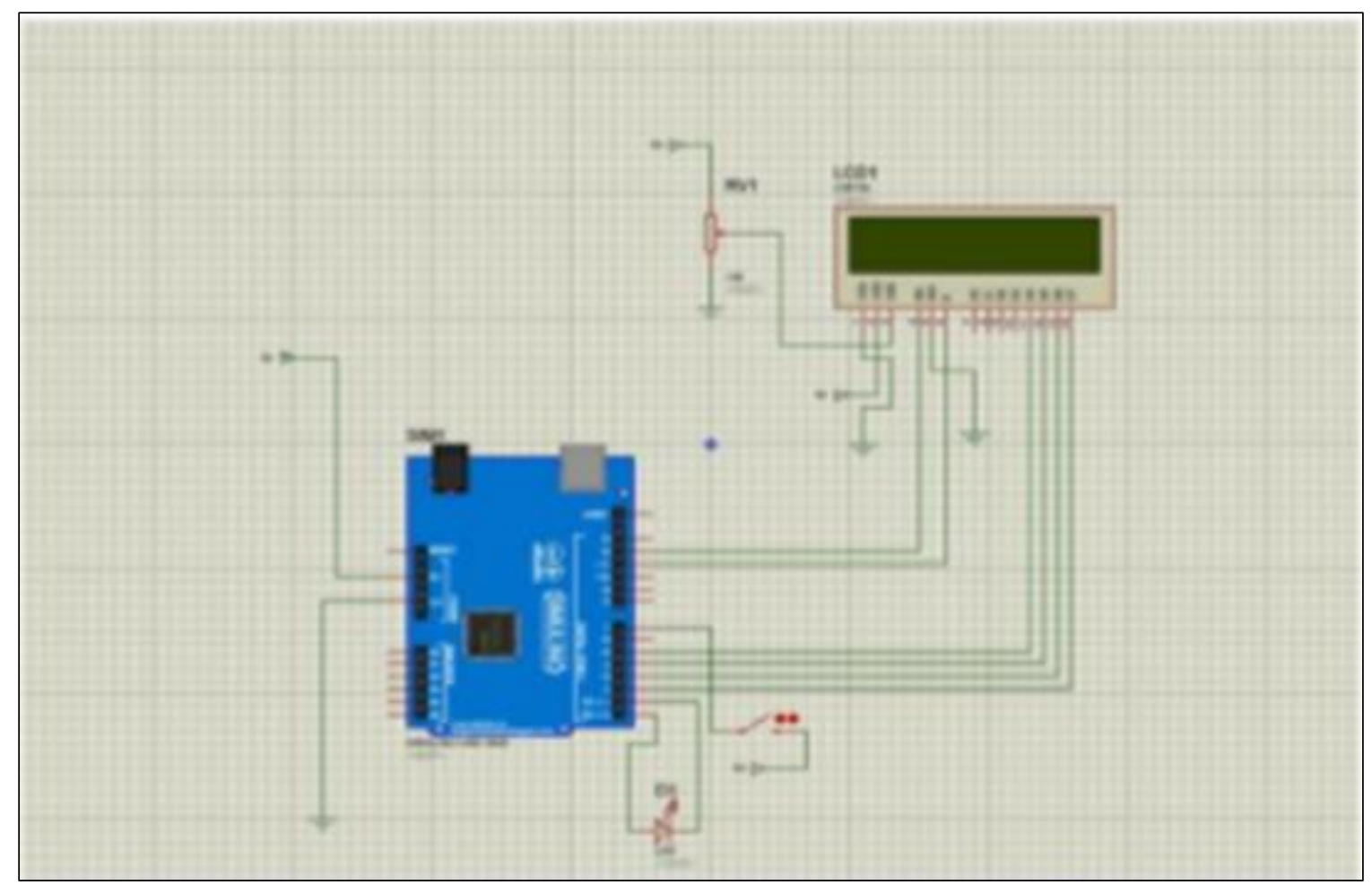

Figure 7: Project schematic diagram.

Source: Authors, (2020).

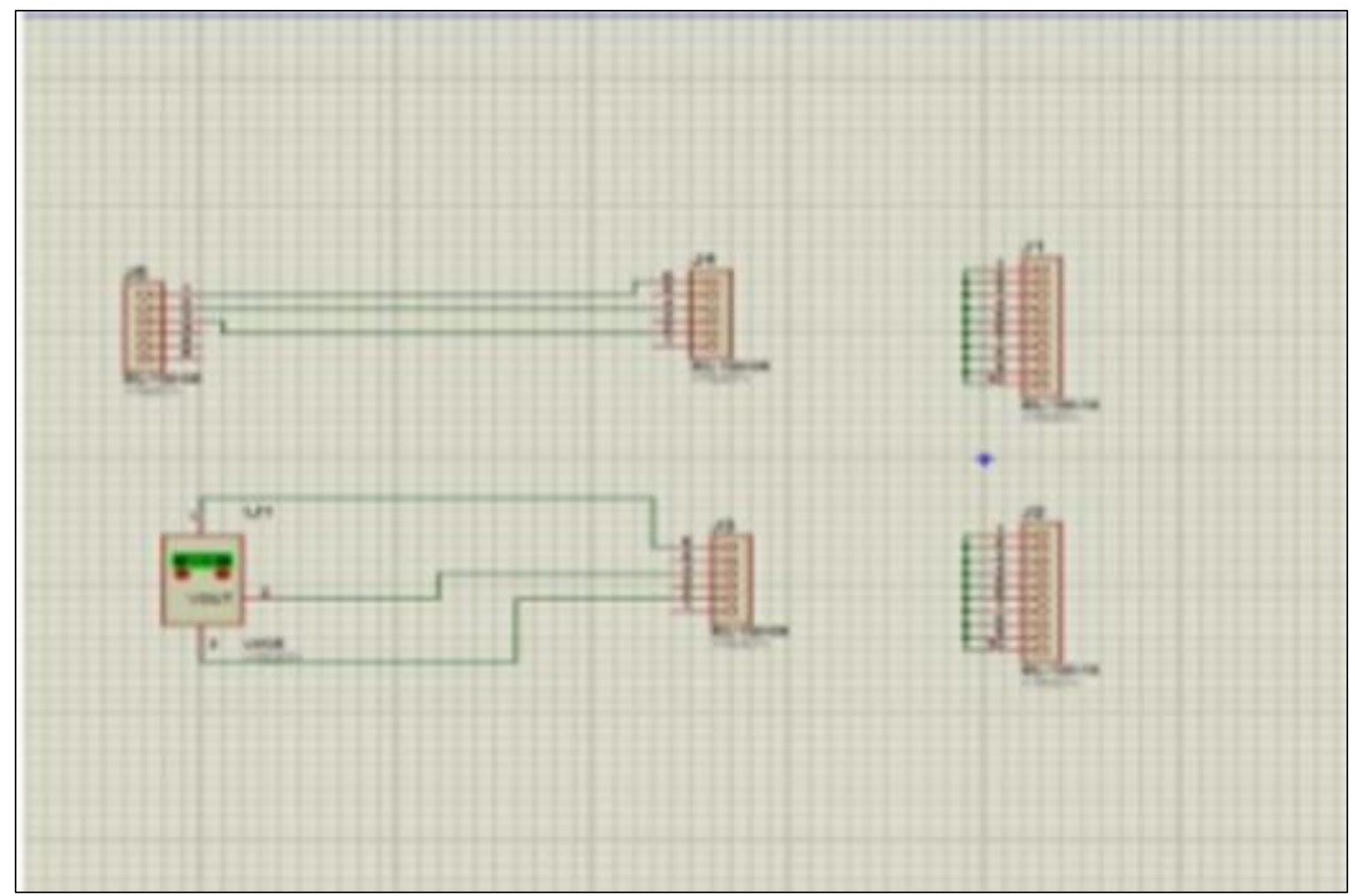

Figure 8: The schematic diagram for connection.

Source: Authors, (2020). 


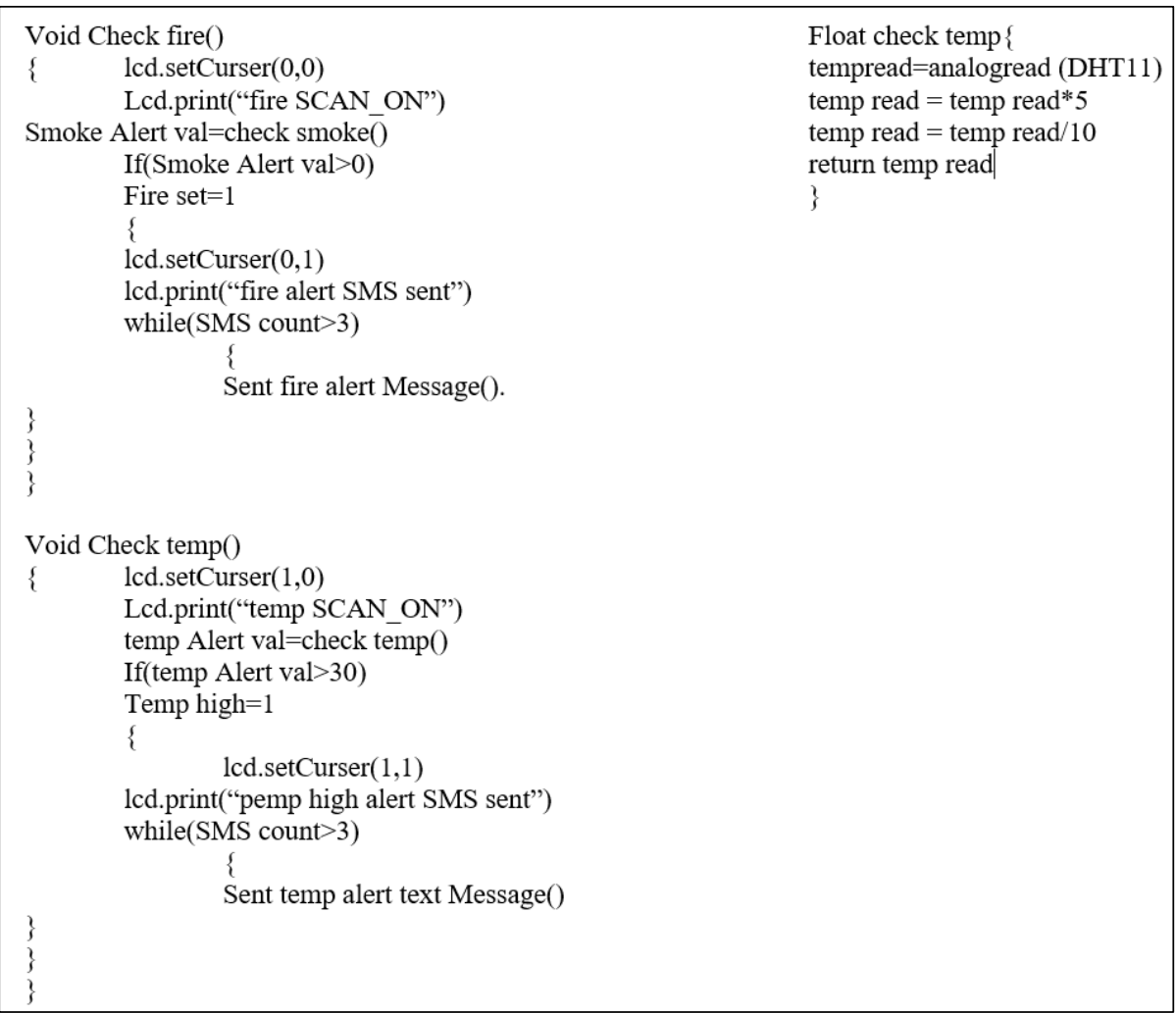

Figure 9: The program code for detect smoke and measuring temperature. Source: Authors, (2020).

\section{RESULTS AND DISCUSSIONS}

Few tests were done to observe the system's performance. The tests were completed by applying smoke near to the MQ5. Figure 10 shows the condition in which the MQ5 is in ready mode (ready to detect smoke) and DHT11 in ready mode (ready to detect temperature). Figure 11 displays alert messages on the LCD when MQ5 detected fire and DHT11 detected temperature increase. While figure 12 reveals the SMS received by the user when a fire or temperature increase alert is notified by the system.

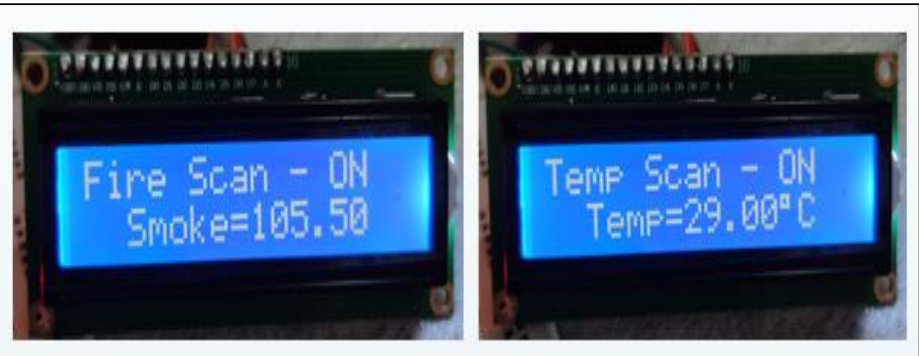

Figure 10: MQ5 is in ready mode and DHT11 in ready mode. Source: Authors, (2020).

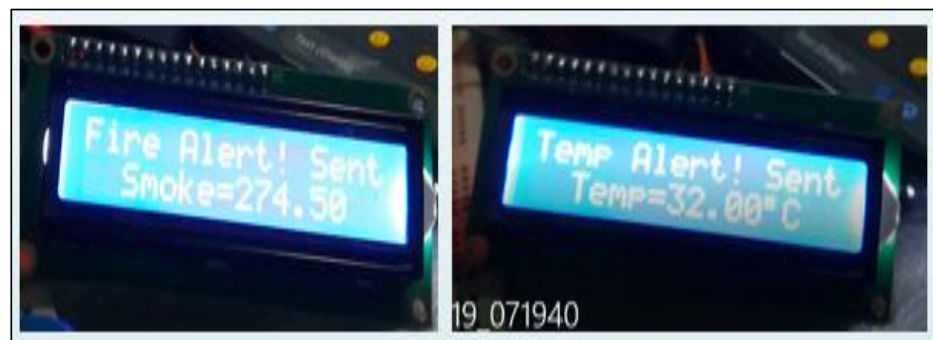

Figure 11: Alert messages on the LCD when MQ5 detected fire and DHT11 detect temperature increase.

Source: Authors, (2020).

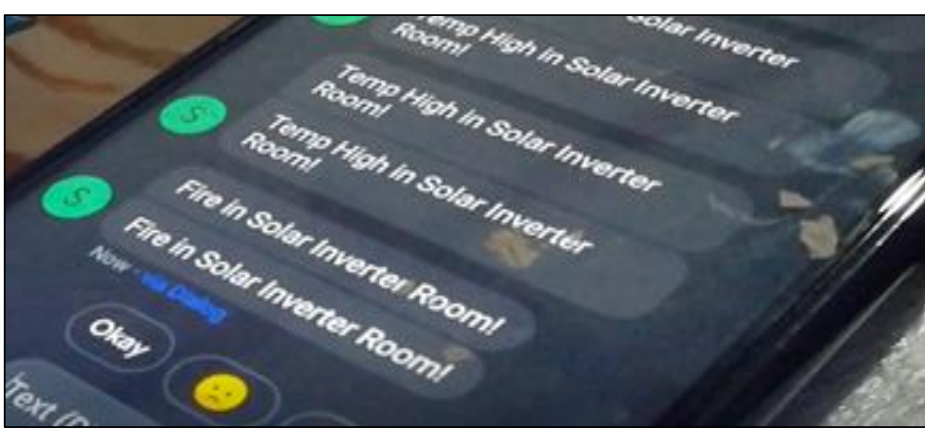

Figure 12: SMS received by the user. Source: Authors, (2020).

As per the results, this system works when a certain level of smoke detected during fire breakout or the temperature increased more than a certain value, was detected. LCD revealed the smoke and temperature alerts and simultaneously a signal was sent to the GSM module. Then GSM module sent an alert SMS to the user's mobile phone. The important part of this system was the power shutting down technique, which was activated during a fire breakout. This is helpful to minimize the damage that could occur due to fire breakout. Therefore this GSM based fire and high-temperature detection system can be easily and effectively applied to premises even where human interaction is limited.

\section{CONCLUSIONS}

This project has been made to help the responsible person of "Solar Inverter Room", to overcome the problem that occurred when fire spreading or temperature increasing happened whenever the responsible person is not in nearby. Based on the results obtained, the fire alert system is doable and functional to the residents, factories to protect their assets. The system built, is cheap in value compared to other existing fire alarm systems in 
the market and easy to apply to the residents also. Users can simply apply the device in their interested area to protect the area from the existence of fire and heat. Whenever the temperature reaches the limit $\left(30^{\circ} \mathrm{C}\right)$ or the smoke level reaches its limit, the device will instantly alert the users by sending a message via GSM. This System can be applied in varied areas due to its flexibility and simplicity in handling; for instance in houses, hostels, hotel industries, factories, material storage areas, warehouses, and many more areas that are related to the gathering of people or valuable assets.

\section{AUTHOR'S CONTRIBUTION}

Conceptualization: Manjula Welihinda and Hasitha Nuwan.

Methodology: Ravindra Koggalage, Manjula Welihinda and Hasitha Nuwan.

Investigation: Ravindra Koggalage, Manjula Welihinda and Hasitha Nuwan.

Discussion of results: Ravindra Koggalage and Hasitha Nuwan.

Writing - Original Draft: Ravindra Koggalage and Hasitha Nuwan.

Writing - Review and Editing: Ravindra Koggalage, and Hasitha Nuwan.

Resources: Ravindra Koggalage, Manjula Welihinda and Hasitha Nuwan.

Supervision: Ravindra Koggalage, Manjula Welihinda.

Approval of the final text: Ravindra Koggalage.

\section{REFERENCES}

[1] L Chun-yuan, "Design of Intelligent Fire Alarm System Based on GSM Network,” no. Iceoe, pp.393-396, 2011.

[2] M Faris, M Fuzi, A F Ibrahim, M. H. Ismail, N. Syakira, and A. Halim, "HOME FADS : A Dedicated Fire Alert Detection System Using ZigBee Wireless Network," pp. 53-58, 2014.

[3] S Suresh, "Home Based Fire Monitoring And Warning System,” 2016.

[4] H Elbehiery, "Developed Intelligent Fire alarm system," Jounal Am. Sci., vol. 2, no. August, pp.1016-1025, 2012.

[5] K Sen, J Sarkar, S Saha, A Roy, D Dey, and S Baitalik, "Automated Fire Detection and Controlling System," Int. Adv. Res. J. Sci. Eng. Technol., vol. 2, no. 5, pp. 34-37, 2015.

[6] P Y Mulge, "Remote Temperature Monitoring Using LM35 sensor and Intimate Android user via C2DM Service,” vol. 2, no. June, pp. 32-36, 2013. 